Indonesian Journal of Biotechnology, June, 2014

Vol. 19, No. 1, pp.33-42

\title{
Effects of Light Quality on Vegetative Growth and Flower Initiation in Phalaenopsis
}

\author{
Kumala Dewi ${ }^{1}$, Yekti Asih Purwestri ${ }^{1}$, Yohana Theresia Maria Astuti ${ }^{2}$, \\ Lila Natasaputra ${ }^{3}$ and Parmi $^{1}$
}

\author{
${ }^{1}$ Faculty of Biology Universitas Gadjah Mada, Indonesia \\ 2 Faculty of Agriculture "INSTIPER", Jl. Nangka II, Maguwoharjo, Depok, Sleman, \\ Yogyakarta 55282, Indonesia \\ ${ }^{3}$ Green Leaves Orchids, Jl. Sinoman Tempel III/235, Salatiga, Cental Java-Indonesia
}

\begin{abstract}
The effects of LEDs (Light-Emitting Diodes) emitting different colours namely red, blue, red and blue, and white lights on vegetative growth and flower initiation of Phalaenopsis have been evaluated. Phalaenopsis"otohine/taisuco fire bird" seedlings in vitro were subjected to different light qualities for either 2 or 4 weeks, and then each seedling was planted in a plastic pot containing sphagnum and grown in the growth chamber under similar light quality for 3 months. For flower induction, mature Phalaenopsis plants having $4-6$ leaves were grown for 3 months in the growth chamber under different light qualities. The leaf span, chlorophyll, gibberellin and cytokinin content were determined. In addition, the expressions of FT-like gene in the leaf, axillary bud, flower bud and stalk were examined.

Vegetative growth was enhanced under blue, red-blue or white LEDs compared to that of the control. Gibberellin and cytokinin content increased in the seedlings subjected to white LEDs. Based on the average of leaf span increment it was suggested that the growth of Phalaenopsis seedlings can be promoted by giving either blue, red-blue or white LEDs. From the second experiment, it was found that flower induction in Phalaenopsis can be obtained in plants that had just finished flowering without the application of LEDs. The expression of FT-like gene in the leaf as well as flower bud and stalk suggests that this gene is involved in flower regulation of Phalaenopsis.
\end{abstract}

Keywords: Light Emitting Diodes (LEDs), Phalaenopsis, gibberellin, cytokinin

\section{Introduction}

Orchids consist of ca.25,000 species, but only few are grown at a large scale in greenhouse for commercial purposes especially epiphytic species. One of these epiphytic orchids is Phalaenopsis. In the natural habitat, Phalaenopsis grows well at high humidity and good shade. Similar to that of many other flowering plants, Phalaenopsis requires specific environment conditions both for their juvenile phase and

\section{*Corresponding author:}

Kumala Dewi

Faculty of Biology, Jl. Teknika Selatan, Yogyakarta 55281

Email: kumala.dewi@ugm.ac.id for flower induction. In a large commercial nursery, plants normally grown in separate greenhouses with different temperatures during these two phases or alternatively plants were grown in different altitudes, and it means that growers should have two nurseries. This cultivation technique is relatively costly and new technique to alter the microclimate for vegetative and flower forcing of Phalaenopsis is still required.

During the vegetative phase, the provision of sufficient light is important to the development of healthy leaves and roots. For cultivation in tropical conditions, it was suggested that $85-90 \%$ shading is required. For example, Leite et al. (2008) reported that various orchids grown under a blue shade net 
resulted in favorable leaf development (e.g., vigor, greater leaf area, more green color) compared to plants that growing under a black shade net. It was suggested that a better appearance of vegetative phase of those orchids was enhanced by the blue shade net was due to the increases of chlorophyll and other pigment biosynthesis through the regulation of the expression of some genes.

Flower initiation or control of flowering time is often applied by orchid growers to obtain flowers at a certain time of the year when the demand increases. Before plants can be forced to flower, the leaves or meristems must reach a condition called 'ripeness to respond'. There are several factors affecting flowering, such as temperature, photoperiod, fertilizers, plant hormones, and even mechanical practices like prunning and leaf trimming (Chomchalow, 2004). For Phalaenopsis, flower forcing can be done either by adjusting the temperature or hormones application. Newton and Runkle (2009) reported that Phalaenopsis require a day temperature of $26{ }^{\circ} \mathrm{C}$ or less to initiate flowering, whereas temperature during the night has little or no effect on flowering. The requirement of low temperature often can be substituted by application of gibberellin and/or cytokinin (Hanks and Jones, 1984). Blanchard and Runkle (2008) reported that application of benzyl adenin of 200 or 400 $\mathrm{mg} / \mathrm{L}$ caused an earlier flowering (3 - 9 days earlier) in Doritaenopsis and Phalaenopsis, but application of benzyladenin and gibberellin had no effect on inflorescence number and flower number. It was suggested that cytokinins play some roles in inducing flower development of Phalaenopsis but cannot completely substitute for an inductive low temperature. Thus, better technique to force flowering in Phalaenopsis is obviously required. Leite et al. (2008) found that Phalaenopsis grown under red shade net bloomed earlier compared to those grown under black shade net and it was suggested due to earlier floral inflorescence induction.
In this paper, we report a new technique for prompting vegetative growth and flower induction using a LED lamp emitting a differing light spectrum. This light emittingdiode lamp is a solid-state lamp that uses light-emitting diodes as the source of light. The light output of individual LED is small compared to incandescence and compact fluorescence lamps. There are several advantages in using LED lamps, such as lower energy consumption, longer lifetime, improve robustness, smaller size, faster switching, and greater durability (http://www.en.wikipedia.org.wiki/LED_ lamp). The effects of LED lamps have been evaluated on several plant species, however, the responses are species dependent (Nhut and Nguyen, 2010). In Phalaenopsis, it was found that total leaf area were increased under LED compared to those under TFLs (Jao and Fang, 2003; Hsu and Chen, 2010)

Flowering is critical for growth and reproduction in plants and is controlled by both environmental and endogenous conditions. One of the most important factors that control flowering is the plant's response to daylight or photoperiod (Imaizumi and Kay, 2006). In addition to the photoperiodic pathway, the regulation of flowering time involves complex signaling pathways, such as the vernalization, autonomous flowering and gibberellins pathways. There are some genes involved in flowering and among those genes, FLOWERING LOCUS T $(F T)$ is a floral integrator that plays an important role in controlling flowering time. Most recently, the nature of FT and its ortholog as florigen, a mobile flowering signal, has been proposed in tomato, rice, arabidopsis and cucurbits (Lifschitz, et al., 2006; Tamaki et al., 2007; Corbesier et al., 2007; Jaeger and Wigge, 2007; Mathieu et al., 2007; Lin et al., 2007; Notaguchi et al., 2008; Zeevart, 2008). At present, the isolation of FT gene in orchid (Oncidium Gower Ramsey) has been reported. Ectopic expression of On FT in transgenic Arabidopsis plants showed early flowering and losing inflorescence indeterminacy phenotypes. In 
this study we also report the expression of FT-like gene in Phalaenopsis that might be induced by light application and whether this gene is linked to flower induction.

\section{Materials and Methods \\ Effects of light quality on vegetative growth of Phalaenopsis}

Phalaenopsis seedlings used originated from the crosses between Phalaenopsis Golden Peoker 'bl'/Haur Jiu Diamond and Phalaenopsis Brother Lawrence "glos". The in-vitro seeedlings of having leaf length about $3 \mathrm{~cm}$ to $5 \mathrm{~cm}$ and leaf width about $1 \mathrm{~cm}$ to 1.5 $\mathrm{cm}$ were obtained from Green Orchid Nursery (Salatiga). Each bottle that contains 10 to 15 Phalaenopsis seedlings was placed in a growth chamber with distance of $20 \mathrm{~cm} \times 10 \mathrm{~cm}$ (column $\times$ row). The bottle was subjected to light quality which consists of four different colors of LED lamps namely red, blue, red and blue (1: 1), "white" and natural light as control with the duration was for either 2 or 4 weeks. The distance of light source to the bottles was $30 \mathrm{~cm}$, and the plantlets received a 8/16 (light/dark) photoperiod. Five bottles were used for each treatment. After the initial treatment, the seedlings were selected and planted in small transparent pots containing sphagnum as growth media. The juvenile plants (20 plants per treatment) were placed back in the same growth chamber with same light quality and grown for 8 weeks. The seedlings received 8/16 (light/dark) per photoperiod. Watering was applied every other day and fertilizer (Grow more) was applied twice a week at the concentration of $1.5 \mathrm{~g} / \mathrm{L}$. At the end of experiment leaf span increment, chlorophyll, gibberellin and cytokinin content in the leaves were determined.

\section{Effect of light quality on flower forcing of Phalaenopsis}

Young Phalaenopsis plants used were Phalaenopsis "otohine/taisuco fire bird" imported from Taiwan. The plants were of 5-6 months old, grown in transparent plastic pot with sphagnum as growth media. This experiment was carried out in the greenhouse which has the average daily temperature and humidity of $26^{\circ} \mathrm{C} / 80 \%$. The plants were placed inside the growth chamber and light quality treatment was given for 8/16 (light/ dark) per photoperiod. For each treatment, 10 plants were used as replicates. Watering was given every other day and fertilizer Grow more ${ }^{\circledR}$ (according to the manufacture's suggestion) was applied twice a week. All plants were grown for 3 months and at the end of experiment, the leaf span increment, chlorophyll, gibberellin and cytokinin content in the leaf were determined.

\section{Chlorophyll assay}

For the extraction of chlorophyll samples, $0.1 \mathrm{~g}$ of fresh orchid leaves from each plant samples were grounded with 10 $\mathrm{mL} 80 \%$ acetone in a mortar and pestle. The leaf extract was filtered using Whatmann paper No. 1 and then absorbance reading of the clear extract were measured at 646 and $663 \mathrm{~nm}$ using aspectrophotometer. The chlorophyll contents $\left(\mu \mathrm{g} \mathrm{mL} \mathrm{m}^{-1}\right)$ were calculated using Harborne method (1998).

\section{Gibberellin and Cytokinin assay}

For gibberellin and cytokinin extraction procedure, leaf blade of $8 \mathrm{~g}$ were grounded with $40 \mathrm{~mL}$ of $80 \%$ methanol $(\mathrm{MeOH})$. The extract was stirred (250 rotation/ $\mathrm{min}$ ) overnight at $4^{\circ} \mathrm{C}$, after which insoluble material was separated by centrifugation (4800 x g for $8 \mathrm{~min})$. Supernatants were collected into small vials and the methanol and part of the water was removed by evaporation until the final volume was about $30 \mathrm{~mL}$. The volume of the aqueous residue was adjusted to $40 \mathrm{~mL}$ with double distilled water $\left(\mathrm{H}_{2} \mathrm{O}\right)$ and the $\mathrm{pH}$ of each sample was adjusted to 2.5 with $50 \mathrm{mM} \mathrm{HCl}$. Samples were then partitioned 3 times against water saturated ethyl acetate (EtOAc), $15 \mathrm{~mL}$ each time and the ethyl acetate phase was collected. The combined organic phases were partitioned 3 times against freshly prepared 
5\% (w/v) NaHCO3, $15 \mathrm{~mL}$ each time and the water phase was collected. Finally, the combined aqueous phase was adjusted to $\mathrm{pH} 2.5$ with concentrated $\mathrm{HCl}$ and again each sample was partitioned 3 times against water saturated EtOAc, $15 \mathrm{ml}$ each time and the ethyl acetate phase was collected. Subsequently all samples were concentrated to dryness and then dissolved in $1000 \mu \mathrm{L}$ $\mathrm{MeOH}$.

\section{High Performance Liquid Chromatography}

Gibberellins and cytokinin were resolved by reverse-phase $\mathrm{C}_{18}$ HPLC (column $\mathrm{C}_{18}$ ' $250 \mathrm{~mm} \times 4.6 \mathrm{~mm}$ i.d. $\times 5 \mu \mathrm{m}$ ). The column temperature was mantained at constant $(25+$ $0.1^{\circ} \mathrm{C}$ ). The separation was carried out by automated isocratic elution with a flow rate of $1 \mathrm{~mL} /$ minute, and wave length of $254 \mathrm{~nm}$. An injection volume of $8 \mu \mathrm{L}$ was used for each analysis. The standard solution of the individual hormone was prepared in the mobile phase and chromatographed separately to determine the retention time for each hormone. The mobile phase was acetonitrile water (30:70\%; v/v) containing $30 \mathrm{mM}$ phosphoric acid with $\mathrm{pH} 4$. The signal of the compound was monitored at $254 \mathrm{~nm}$. The relative concentration of hormones were determined by comparing the peak area of samples to each hormone standard (Kelen et al., 2004).

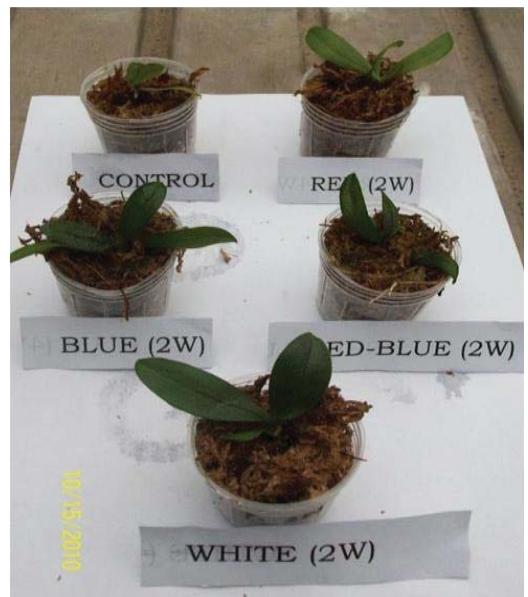

(a)

\section{RT-PCR analysis}

The total RNA was extracted from dissected leaf axis of Phalaenopsis plants that had been subjected to different light qualities using a Trizol kit (Invitrogen) according to the manufacturer's protocol. First-strand cDNA synthesis was carried out using $1 \mu \mathrm{g}$ of total RNA with oligo dT primer according to the protocol of the RT-PCR Kit (Invitrogen). First-strand cDNA was used to amplify FT-like gene of Phalaenopsis via PCR using degenerate primers, based on the conserve region of Rice Hd3a gene, namely: Hd3aF(5'-CTTGTGGTTGGTAGGGTTGT-3') and Hd3a-R (5'-TTCGCCGAGCTCTACAACCT CGT-3'). As the positive control, a pair of primers of the ubiquitin cDNA namely UBQ$\mathrm{F}\left(5^{\prime}\right.$-CACAAGAAGGTGAAGCTCGC-3') andUBQ-R (5'CCTTCTGGTTGTAGACGTA GG-3') was used to amplify Phalaenopsis ubiquitine cDNA.

\section{Results and Discussion}

Light is one of most important factors known to regulate the growth of Phalaenopsis. Previous experiments demonstrated that Phalaenopsis grown under a blue shade net displayed more commercially appealing leaf traits e.g., more green, more reflective leaves, compared to those grown under

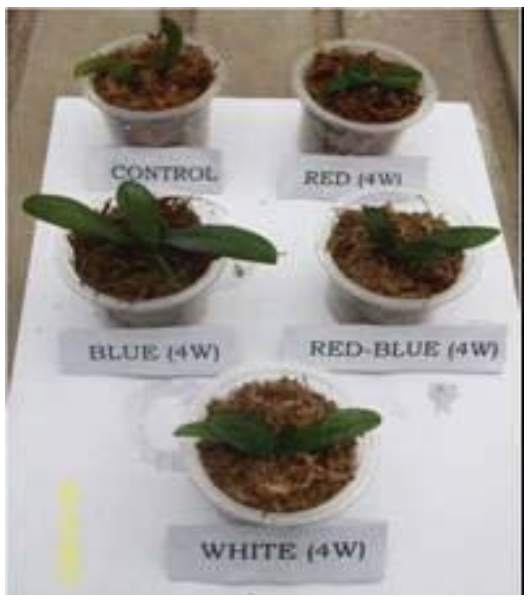

(b)

Figure 1. Phalaenopsis seedlings after grown in various light quality for 2 weeks (a) or 4 weeks (b) 


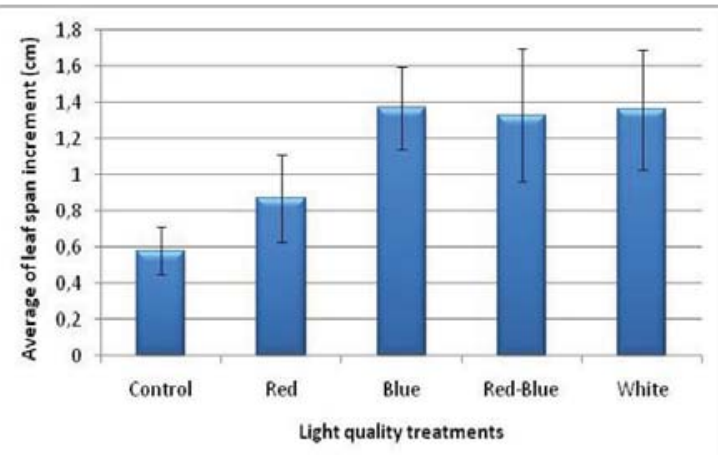

Figure 2. The average \pm SE of leaf span increment of Phalaenopsis seedlings grown under different light quality for 3 months $(n=6)$

ablack shade net (Leite et al., 2008). In this experiment, Phalaenopsis seedlings grown under control condition showed thinner leaves compared to those grown in the growth chamber with different light quality. This might be attributed to high transpiration rates that could have resulted from higher temperatures under greenhouse conditions (i.e., $30 \pm 2{ }^{\circ} \mathrm{C}$ ). For Phalaenopsis seedlings grown in the growth chamber, the humidity and water availability in the growth media can be well maintained and it leads to the better growth of seedlings. Moreover, the value of leaf span increment of seedlings grown in blue, red-blue, or white LEDs are greater than control (Figure 1a. and 1b.), where as seedlings grown under red LEDs showed no significant leaf span increment compared to control (Figure 2). These results indicate that photosynthesis process under blue, red and blue or white light possibly are better than red LEDs or control condition. This assumption was based on the fact that the total chlorophyll contents also higher in those seedlings compared to those seedlings grown under red LEDs or control condition (Figure 3 and Figure 4)

It was suggested that blue light controls stomatal conductance rather than red light, and that red LEDs may cause lower photosynthesis through lower stomatal condustance. In addition, the narrow peak emission of red LEDs also leads to an imbalance of photons available to both

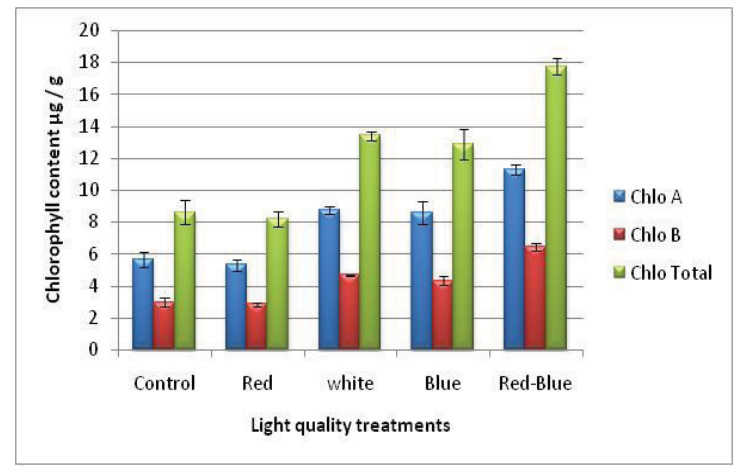

Figure 3 . The average \pm SE chlorophyll contentin Phalaenopsis seedling treated with different light quality ( 2 weeks in the bottle followed by 3 month grown under similar light quality) $(\mathrm{n}=5)$

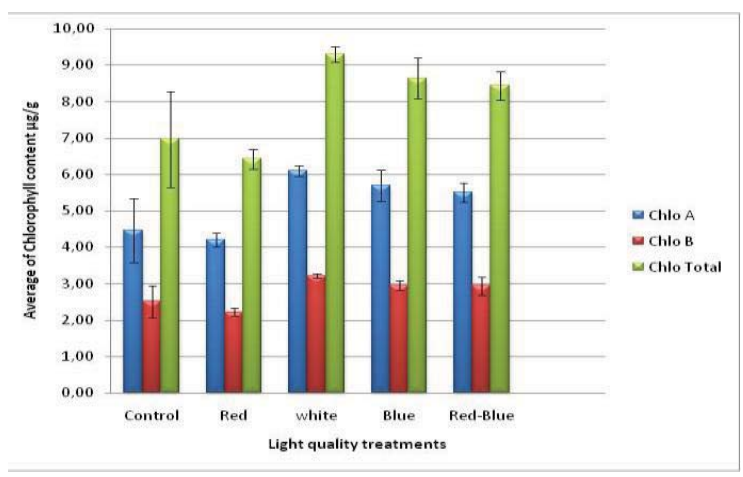

Figure 4 . The average \pm SE chlorophyll content in Phalaenopsis seedling treated with different light quality (4 weeks in the bottle followed by 3 months grown under similar light quality) $(n=5)$

photosystem I and II, thus altering the ratio of cycle to whole chain reaction transport, and causing a reduction in net photosynthesis (Nhut and Nguyen, 2010). However, in Paphiopedilum, red light given together with blue light enhanced stomatal opening (Talbott et al., 2002), whereas Jao and Fang (2003) found that for Phalaenopsis plantlets in vitro grown under red-blue LEDs only show a slight increase in leaf length compared to those plants grown under TFLs.

The content of gibberellin and cytokinin determined in Phalaenopsis seedlings showed that only white LEDs gave higher content of both hormones compared to control (Figure 4 and Figure 5). This results indicate that the synthesis of hormones are better under 


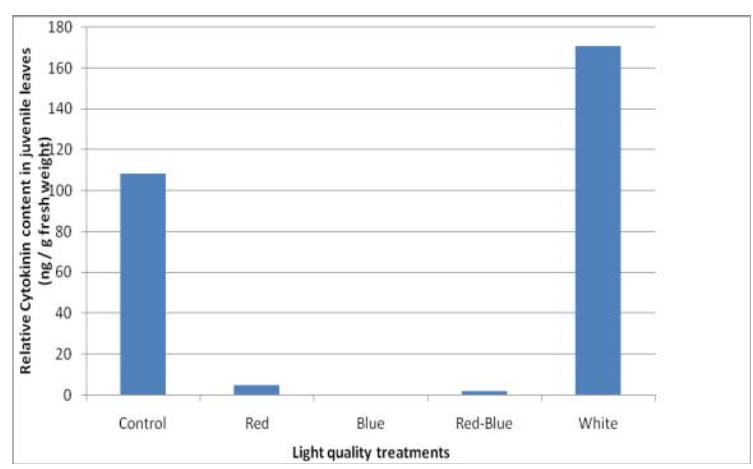

Figure 5. The average relative content of gibberellin in Phalaenopsis seedlings grown under different light quality for 3 months $(n=3)$

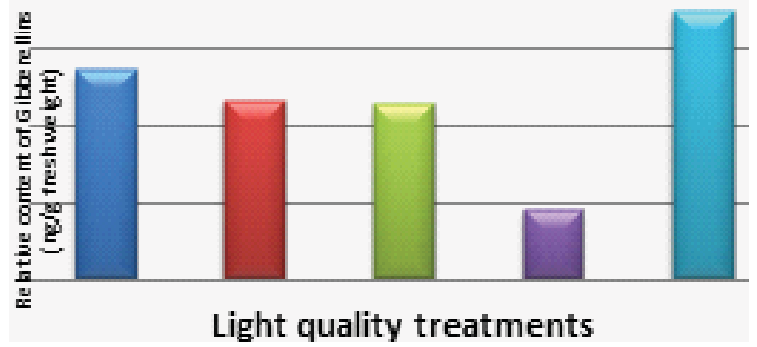

Figure 6. The average relative content of cytokinin in Phalaenopsis seedlings grown under different light quality for 3 months $(\mathrm{n}=3)$

white light that can gave all spectrum of light. The relative content of gibberellin can be detected in seedlings grown under red, blue or red-blue LEDs but cytokinin content was very low. It could be due to the synthesis of cytokinin which mostly occurred in roots (Aloni, 2005), and for the seedlings observed there were only few roots developed during the three months growth.

\section{Effect of light quality on flower initiation and expression of FT-like gene in Phalaenopsis}

Flowering is regulated by several factors and for Phalaenopsis it was known that temperatureand humidity play important roles in flower initiation. In this experiment the effect of light quality on triggering flower initiation of Phalaenopsis was evaluated. However,all Phalaenopsis plants subjected to different light quality failed to flower. This maybe attributed to the young age of Phalaenopsis and longer duration might be required to induce flowering, as well as light quality. Phalaenopsis plants used in this experiment had 4-6 leaves and had yet to flower. Eventhough these plants were considered as mature plants, the transition from vegetative to reproductive stage can not be forced by different light quality given for 3 months. This assumption is supported by the fact that additional mature Phalaenopsis plants that just finished flowering can be forced to initiate flowering again under control condition in the same greenhouse area, and flowering can be initiated within less than a month. It seems that for Phalaenopsis, the age of plant is important in induction of flowering. The availability of assimilate required for flowering possibly more in mature plant. The leaf growth was observed in the youngest leaves of Phalaenopsis, however, different light quality

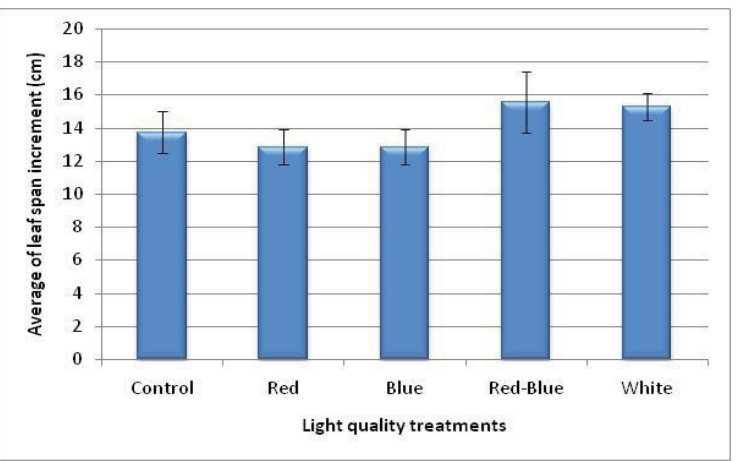

Figure 7. The average \pm SE of leaf span increment of mature Phalaenopsis grown under different light quality for three months $(n=6)$

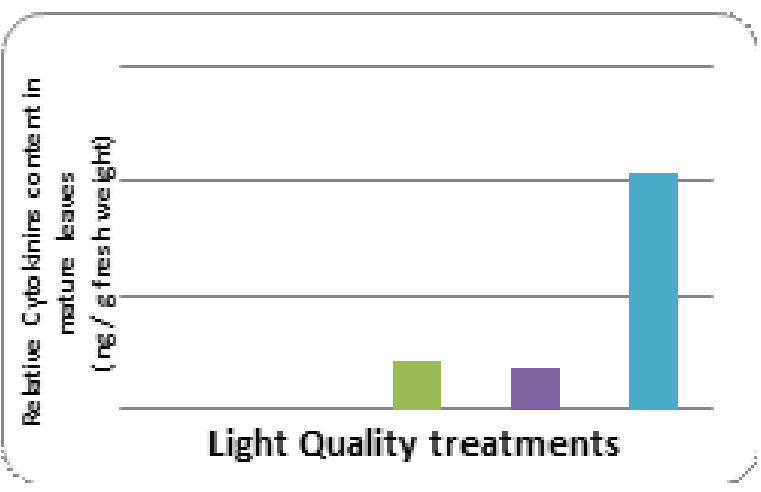

Figure 8 . The average relative content of gibberellin in mature Phalaenopsis grown under different light quality for 3 months $(n=3)$ 


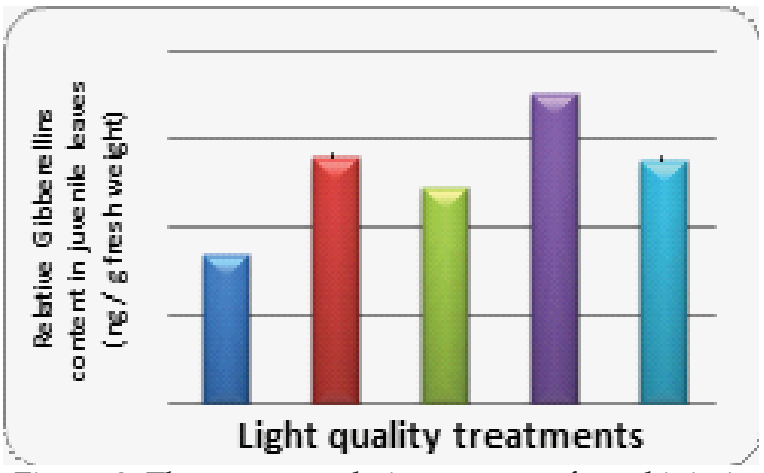

Figure 9. The average relative content of cytokinin in mature Phalaenopsis grown under different light quality for 3 months $(n=3)$

used in this experiment showed no effect on the average of leaf span increment during three months growth of the plants (Figure 6). Eventhough all LEDs gave relatively bright light, the radiation energy required to promote photosynthesis in the developing leaves of mature plant is not sufficient. The average of total chlorophyll contents in the fully developed leaf of Phalaenopsis plants grown under red or white LEDs was relatively similar to control (ca. $11 \mu \mathrm{g} / \mathrm{g}$ fresh weight). Blue LEDs caused a slight decrease in total chlorophyll content, but red-blue LEDs caused a slight increase in total chlorophyll content compared to that of the control.

For gibberellin content in the leaves, it was shown in Figure 9. that light quality treatments tend to increase the relative content of gibberellin compared to that of control. Similar finding also found for relative cytokinin content (Figure 10), except that under control or red LEDs, cytokinin content was not detected, on the other hand under white LEDs, cytokinin content was the highest ( $10 \mathrm{ng} / \mathrm{g}$ fresh weight and it is about 5-fold compared to the relative cytokinin content in the plants grown under blue or red-blue LEDs). As cytokinin is mainly synthesized in the roots, this result showed that transport of cytokinin to the leaves was promoted by white LEDs.

Relative content of gibberellin in the leaf and roots are of $162 \mathrm{ng} / \mathrm{g}$ FW and 1492 ng/g FW respectively, whereas relative cytokinin content only detected in the roots (6.15 ng/FW). These results indicate that during flowering of Phalaenopsis, a relatively high gibberellin content in the roots is required. In Arabidopsis, the relationship between gibberellin and Flowering Locus $\mathrm{T}(F T)$ has been evaluated. It was suggested that FT protein acts as a floral signal and that gibberellin promote flowering through an independent pathway or by increasing the relative expression level of FT mRNA (Hisamatsu and King, 2008). In Miltoniopsis orchids, gibberellin application of 2.5 $\mathrm{mM}$ hasten the initiation of inflorescence during the first flowering season and it also increased the number of inflorescence per plant (Matsumoto and Brower, 2006). An application of gibberellin to the roots probably can speed up flowering time in Phalaenopsis.

The gene(s) that regulate flowering are commonly expressed during the transitional phase from vegetative to reproductive stage. The four major pathways that commonly controlled the initiation of flowering are photoperiode, vernalization, hormones and autonomous regulation (Simpson et al., 1999 in Cheng and Chang, 2009). The Flowering locus $\mathrm{T}(F T)$ gene plays a crucial role in transition of vegetative phase to flowering. In Oncidium Grower Ramsey it has been reported that On FT mRNA was expressed in axillarry buds, leaves, pseudobulb and flower and that the expression was regulated by photoperiod. The over expression of OnFT in transgenic Arabidopsis plants caused an early flowering and losing inflorescence indeterminancy (Cheng and Chang, 2009).

In this experiment, the expression of FT-like gene in Phalaenopsis was investigated by semi quantitative PCR. The cDNA was synthesized from axillary bud of mature Phalaenopsis plant that had been subjected to different light quality, as well as from leaf axillary bud, and flower bud+stalk of Phalaenopsis plants that showed transition from vegetative to reproductive and flowering stage. It was found that FT-like gene was 


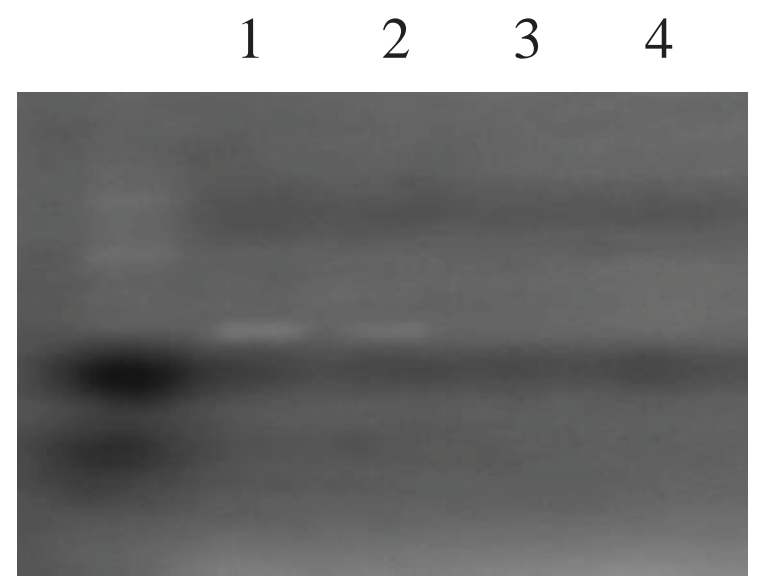

Figure 10. FT-like gene expression of Phalaenopsis sp by RT-PCR. Lane number 1-4 are FT-like gene of Phalaenopsis sp. grown under white, blue, red and red-blue LEDs, respectively. Total RNA isolated from axillary bud of Phalaenopsis sp. was used as template to detect the expression of FT-like gene. $M=$ marker $100 \mathrm{bp}$

expressed in the leaf axis of plants that had been subjected to white or blue LEDs (Figure 9). This result may suggest that if the plants were allowed to grow longer, promotion of flower initiation in plants grown under white or blue LEDs can be observed. The expression of FT-like gene in Phalaenopsis plant showing the transition of vegetative to reproductive stage and flowering stage were also evaluated. It was found that FTlike gene was detected in the leaves of plant in the transition of vegetative to reproductive stage, whereas in plants that already showed flower development, FT-like gene expression was found in flower bud + stalk (Figure 10). This result supports the finding of On FT mRNA expression which is higher in young flower buds rather than mature flowers (Cheng and Chang, 2009). In Arabidopsis it has been shown that FT mRNA is transiently expressed in leaf vascular tissue, and that FT protein acts as a long distance that induce flowering (Corbesier et al., 2010)

\section{Conclusion}

Based on the data of leaf span increments, chlorophyll content and hormone content, it can be inferred that the growth of Phalaenopsis seedlings can be promoted by giving either blue, red-blue or white LEDs. In addition, flower initiation in Phalaenopsis can be obtained in plants that had just finished flowering without LEDs application. For plants that will be forced for first flowering, a longer duration more than three months is required and it possibly blue or white LEDs can act as trigger for flowering. An application of gibberellin to roots probably can also accelerate flowering in mature Phalaenopsis. The expression of FT-like gene in the leaf as well as flower bud + stalk suggests that this gene involves in flower regulation of Phalaenopsis.

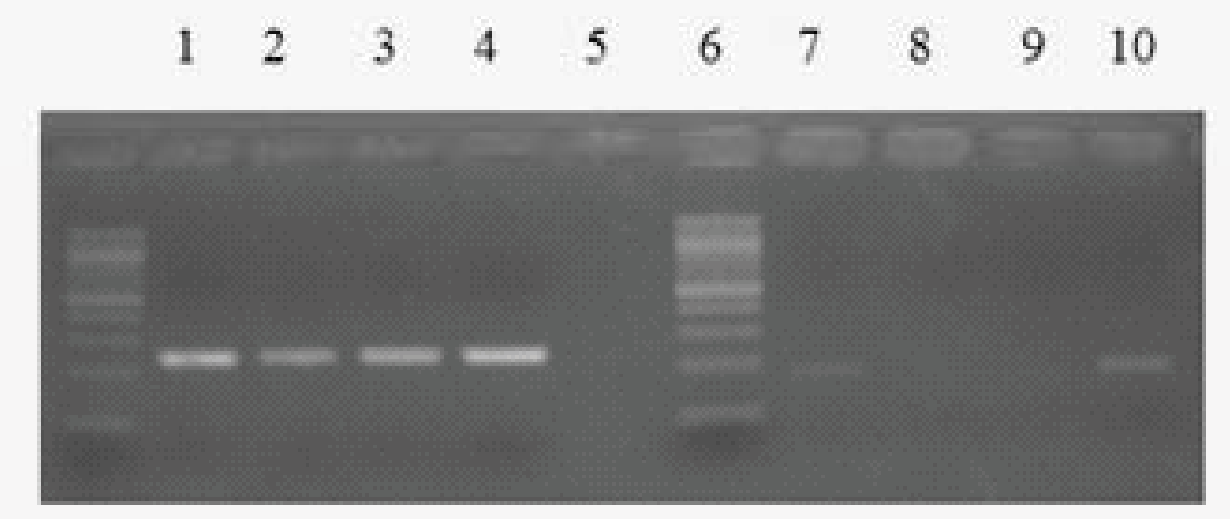

Figure 11. Ubiquitin and FT-like gene expression of Phalaenopsis sp by RT-PCR. Lane number 1-4 are ubiquitin expression of Phalaenopsis sp. grown under white, blue, red and far red lights, respectively.Total RNA isolated from leaf (lane 7) and axillary bud (lane 8) of Phalaenopsis sp during transition from vegetative to reproductive stage, was used as template to detect the expression of FT-like gene. Lane 9 and 10 shows leaf and flower bud+stalk FT-like gene expression during reproductive stages, respectively. $\mathrm{M}=$ marker $100 \mathrm{bp}$ 


\section{Acknowledgements}

The authors would like to thank the Head Office of UPTD-BP2APH, Dinas Pertanian, Propinsi D.I.Yogyakarta and the Head Laboratory of Plant Tissue Culture, Faculty of Biology, Universitas Gadjah Mada for giving permission to the researchers in utilizing greenhouse facility. Our gratitude thanks are also given to Ms. Arsiyanti, Mr. Martono, Mr. Giman and Mr.Sulis for technical assistance. This work was supported by grants to K.D from Indonesia-Managing Higher Education for Relevance and Efficiency (I-MHERE) Project Research Grant. Letter ofAgreement No. UGM/BI/1627/I/05/04, June 3rd, 2010.

\section{References}

Aloni, R., Langhans, M., Aloni E., Dreieicher, E. And Ullrich, C.I., 2005. Root-synthesized cytokinin in Arabidopsis is distributed in the shoot by the transpiration stream. Journal of Experimental Botany, 56(416): $1535-1544$

Blanchard, M.G. and Runkle E.S., 2006. Temperature during the day, but not during the night, controls flowering of Phalaenopsis orchids. Journal of Experimental Botany, 57(15) : 4043 - 4049

Cheng, J.H. and Chang-H.Y., 2009. Functional Analysis of FT and TFL1 Orthologs from Orchid (Oncidium Gower Ramsey) that regulate the vegetative to Reproductive Transition). Plant Cell Physiol, 50(8): 15441577.

Chomchalow, N. (2004). Flower forcing for cut flower production with special reference to Thailand. Assumption University J.T. 7(3) : 137- 144

Corbesier, L., Vincent, C., Jang, S., Fornara, F., Fan, Q., Searle, I., 2007. FT protein movement contributes to long-distance signaling in floral induction of Arabidopsis. Science, 316:1030 -1033.

Hanks, G.R. and Jones, J.K.. (1984). Gibberellin treatmets in bulb forcing. In : Annual report
The Glass House Crop Research Institute. Rustington Little Hampton, West Sussex BN 163 PV. Pp : 73 - 75

Harborne, J.B. 1998. Phytochemical methods. Aguide to modern techniques of plant analysis. Third Edition. Chapman \& Hall. London, UK.

Hisamatsu, T. and King, R.W., 2008. The nature of floral signals in Arabidopsis. II. Roles for FLOWERING LOCUS T (FT) and gibberellin. Journal of Experimental Botany, 59 (14) : 3821 - 3829

Hsu, H-C.and Chen C.C., 2010. The effect of light spectrum on the growth characteristics of Invitro cultures of Phalaenopsis. Propagation of Ornamental Plants, 10(1) : 3 - 8

Imaizumi, T. and Kay, S., 2006. Photoperiodic control of flowering: not only by coincidence. Trends in Plant Science, 11: 550-558.

Jao, R.C. and Fang, W., 2003. An adjustable light source for photo-phyto related research and young plant production. Applied Engineering in Agriculture, 19(5): $601-608$

Jaeger, K. and Wigge, P., 2007. FT protein acts as a long-range signal in Arabidopsis. Current Opinion in Biology, 17: 1050 $-1054$.

Kelen, M., Demilaray, E.C., Sen, S. and Ozkan, G., 2004. Separation of abscisic acid, indole3-acetic acid, gibberellic acid in 99R (Vitis berlandieri $x$ Vitis rupestris) and Rose oil (Rosa damascena Mill.) by Reversed Phase Liquid Chromatography. Turkey J of Chem, $28: 603-610$

Leite, C.A., Ito, R.M., Gerald, L.T.C, Ganelevin, R. and Fagnani M.A., 2008. Light spectrum management using coloured nets aiming to controlling the growth and the blooming of Phalaenopsis sp. Acta Horticulturae, 393: 189 - 194.

Lifschitz, E., Eviatar, T., Rozman, A., Shalit, A., Goldshmidt, A., Amsellem, Z. (2006). The tomato FT ortholog triggers systemic signals that regulate growth and flowering and substitute for diverse environmental 
stimuli. Proceeding National Academic of Science. USA 103: 6398 - 6403.

Lin, M.K., Belanger H., Lee, Y.J., VarkonyiGasic, E., Taoka, K., Miura, E., XoconostleCázares, B., Gendler, K., Jorgensen, R.A., Phinney, B., Lough, T.J., Lucas, W.J., 2007. FLOWERING LOCUS T protein may act as the long-distance florigenic signal in the cucurbits. Plant Cell, 19 :1488-1506

Mathieu, J., Warthmann, N., Kuttner, F. and Schmid, M., 2007. Export of FT protein from phloem companion cells is sufficient for floral induction in Arabidopsis. Current Opinion in Biology, 17: 1055 -1060

Matsumoto and Brower, T.K., 2006. Gibberellic acid and benzyladenin promote early flowering and vegetative growth of Miltoniopsis orchid hybrid. Horticultural Science, 41: 131 - 135

Newton, L.A. and Runkle E.S., 2009. High temperature inhibition of flowering of Phalaenopsis and Doritaenopsis orchids. Horticulturae Science, 44(5) : 1271 - 1273

Nhut, D.T. and Nguyen B.N.. (2010). Lightemitting diodes (LEDs): An artificial lightning Source for biological studies. Proceeding of the 3rd International Conference on the Development of BME in Vietnam, 11 - 14th Jan. pp: 133 - 138

Notaguchi, M., Abe, M., Kimura, T., Daimon, Y., Kobayashi, T., Yamaguchi, A., Tomita, Y., Dohi, K., Mori, M., Araki, T., 2008. Long-distance, graft-transmissible action of Arabidopsis FLOWERING LOCUS T protein to promote flowering. Plant Cell Physiol, 49: 1645-1658

Talbott, L.D., Zhu, J., Won han, S. And Zeiger E., 2002. Phytochrome and blue-light mediated stomatal opening in the orchid Paphiopedilum. Plant Cell Physiol, 43(6): $634-646$

Tamaki, S., Matsuo, S., Wong, H., Yokoi, S. and Shimamoto, K., 2007. Hd3a protein is a mobile flowering signal in rice. Science, 316: 1033-1036.

Zeevaart, J.A., 2008. Leaf-produced floral signals. Curr Opin Plant Biol, 11:541-547. 